Journal of Proteomics xxx (2015) xxx

Contents lists available at ScienceDirect

Journal of Proteomics

Proteomic changes occurring in the malaria mosquitoes Anopheles gambiae and Anopheles stephensi during aging

Maggy T. Sikulu *, James Monkman, Keyur A. Dave, Marcus L. Hastie, Patricia E. Dale, Roger L. Kitching, Gerry F. Killeen, Brian H. Kay,

Jeffery J. Gorman, Leon E. Hugo

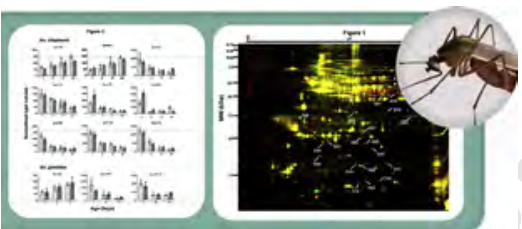


Proteomic changes occurring in the malaria mosquitoes Anopheles gambiae and Anopheles stephensi during aging

Maggy T. Sikulu a,d,*, James Monkman a ${ }^{a}$, Keyur A. Dave ${ }^{a}$, Marcus L. Hastie ${ }^{a}$, Patricia E. Dale ${ }^{\text {b }}$, Roger L. Kitching ${ }^{\text {b }}$, Gerry F. Killeen ${ }^{\mathrm{c}}$, Brian H. Kay a, Jeffery J. Gorman ${ }^{\text {a }}$, Leon E. Hugo ${ }^{\text {a }}$

${ }^{a}$ Mosquito Control Laboratory, QIMR Berghofer Medical Research Institute, Brisbane, Queensland, Australia

${ }^{\mathrm{b}}$ Environmental Research Institute and Griffith School of Environment, Griffith University, Brisbane, Queensland, Australia

c Environmental Health and Ecological Sciences Thematic Group, Ifakara Health Institute, Ifakara, United Republic of Tanzania

${ }^{\mathrm{d}}$ Vector Biology Department, Liverpool School of Tropical Medicine, Liverpool, United Kingdom

- The expression of some A. gambiae and A. stephensi proteins changes with age.

- Mass spectrometry was used to provide identity of age related proteins.

- Age related trends identified by 2-D-DIGE analysis were confirmed by Western blot.

- Antibodies developed against Aedes species cross-react with Anopheles proteins. 


\title{
Q2 Proteomic changes occurring in the malaria mosquitoes Anopheles gambiae and Anopheles stephensi during aging
}

\author{
Q4 Q3 Maggy T. Sikulu ${ }^{\text {a,d,* }}$, James Monkman a , Keyur A. Dave a , Marcus L. Hastie a , Patricia E. Dale ${ }^{\text {, }}$, Roger L. Kitching , \\ Gerry F. Killeen ${ }^{c}$, Brian H. Kay ${ }^{\text {, }}$, Jeffery J. Gorman ${ }^{\text {a }}$, Leon E. Hugo a \\ a Mosquito Control Laboratory, QIMR Berghofer Medical Research Institute, Brisbane, Queensland, Australia \\ ${ }^{\mathrm{b}}$ Environmental Research Institute and Griffith School of Environment, Griffith University, Brisbane, Queensland, Australia \\ c Environmental Health and Ecological Sciences Thematic Group, Ifakara Health Institute, Ifakara, United Republic of Tanzania \\ d Vector Biology Department, Liverpool School of Tropical Medicine, Liverpool, United Kingdom
}

\section{A R T I C L E I N F O}

\section{Article history:}

Received 10 March 2015

Received in revised form 14 May 2015

Accepted 13 June 2015

Available online $\mathrm{xxx}$

\section{Keywords:}

Q6 Age associated protein biomarkers

17 Anopheles gambiae s.s

18 A. stephensi

19 2D-DIGE

20 Mass spectrometry

21 Semi quantitative Western blot analysis

\begin{abstract}
A B S T R A C T
The age of mosquitoes is a crucial determinant of their ability to transmit pathogens and resistance to insecticides. 22 We investigated changes to the abundance of proteins found in heads and thoraces of the malaria mosquitoes 23 Anopheles gambiae and Anopheles stephensi as they aged. Protein expression changes were assessed using two- 24 dimensional difference gel electrophoresis and the identity of differentially expressed proteins was determined 25 by using either matrix-assisted laser desorption ionization tandem time-of-flight mass spectrometry or capillary 26 high-pressure liquid chromatography coupled with a linear ion-trap (LTQ)-Orbitrap XL hybrid mass spectrome- 27 ter. Protein biomarkers were validated by semi quantitative Western blot analysis.

Nineteen and nine age dependent protein spots were identified for A. stephensi and A. gambiae, respectively. $\mathbf{Q 5}$ Among the proteins down-regulated with age were homologs of ADF/Cofilin, cytochome $\mathrm{c} 1$, heat shock 30 protein-70 and eukaryotic translation initiation factor 5A (eIF5a). Proteins up-regulated with age included prob- 31 able methylmalonate-semialdehyde dehydrogenase, voltage-dependent anion-selective channel and fructose 32 bisphosphate aldolase. Semi quantitative Western blot analysis confirmed expression patterns observed by 2 - 33 D DIGE for eIF5a and ADF/Cofilin. Further work is recommended to determine whether these biomarkers are ro- 34 bust to infection, blood feeding and insecticide resistance. Robust biomarkers could then be incorporated into 35 rapid diagnostic assays for ecological and epidemiological studies.

Biological significance: In this study, we have identified several proteins with characteristic changes in abundance 37 in both A. gambiae and A. stephensi during their aging process. These changes may highlight underlying mecha- 38 nisms beneath the relationship between mosquito age and factors affecting Plasmodium transmission and mos- 39 quito control. The similarity of changes in protein abundance between these species and the primary dengue 40 vector Aedes aegypti, has revealed conserved patterns of aging-specific protein regulation.
\end{abstract}

(C) 2015 Published by Elsevier B.V.

\section{Introduction}

Age affects several aspects of mosquito biology relevant to the transmission of mosquito borne disease. It has been shown that older mosquitoes are less susceptible to infection with filarial nematodes and infection increases the mortality rate of older mosquitoes to a greater extent than for younger mosquitoes [1]. Plasmodium malaria parasites can only be transmitted by a small fraction of Anopheles mosquito

* Corresponding author at: Mosquito Control Laboratory, QIMR Berghofer Medical Research Institute, Brisbane, Queensland, Australia.

E-mail addresses: Maggy.Sikulu@qimrberghofer.edu.au (M.T. Sikulu), James.monkman@gmail.com (J. Monkman), Keyur.Dave@qimrberghofer.edu.au (K.A. Dave), Marcus.Hastie@qimrberghofer.edu.au (M.L. Hastie), P.dale@griffith.edu.au (P.E. Dale), R.kitching@griffith.edu.au (R.L. Kitching), gkilleen@ihi.or.tz (G.F. Killeen), Brian.Kay@qimrberghofer.edu.au (B.H. Kay), Jeffery.Gorman@qimrberghofer.edu.au (J.J. Gorman), Leon.Hugo@qimrberghofer.edu.au (L.E. Hugo). population consisting of mosquitoes that survive long enough to sup- 54 port the development of the parasite to the stages infective to humans 55 [2]. The period required for parasite development in the mosquito, 56 known as the extrinsic incubation period, is approximately 9-14 d de- 57 pending on Plasmodium species and ambient temperature [2]. During 58 their development inside mosquitoes, pathogens such as Plasmodium 59 [3] or dengue virus [4] have been reported to induce alterations in the 60 mosquito proteome. It has also been reported that aging increases sus- 61 ceptibility to insecticides of otherwise resistant mosquito species 62 [5-7]. This could be due to alterations in the expression of enzymes 63 that regulate insecticide resistance such as Glutathione Transferase e2 64 (GSTe2) [5].

Aging in general is attributed to increase in oxidative and heat stress, 66 protein misfolding and other events that can eventually lead to loss of 67 cellular function or ability to deal with stress. Aging has therefore 68 been defined as a deteriorative change over time that eventually causes 69 
mortality [8]. At older ages, deteriorative changes have been suggested to be due to a decreased force of natural selection [9]. According to the free radical aging theory, free radical by-products of normal cellular metabolism, such as reactive oxygen species (ROS), cause damaging oxidation of cellular molecules including DNA and proteins $[10,11]$. These oxidised molecules accumulate over time eventually leading to cellular and organ failure. Oxidoreductases can also be major contributors of ROS due to inefficient electron transfer. Superoxide dismutase is an antioxidant enzyme that catalyses the dismutation of the ROS superoxide into $\mathrm{H}_{2} \mathrm{O}_{2}$ and $\mathrm{O}_{2} . \mathrm{H}_{2} \mathrm{O}_{2}$ is also highly detrimental to the cell when left to accumulate; therefore it is converted into $\mathrm{H}_{2} \mathrm{O}$ and $\mathrm{O}_{2}$ by catalases. Recent studies in Aedes aegypti demonstrated changes in abundance of different isoforms of SOD2 during aging, suggesting that aging is associated with post-translational modification of this stress response enzyme [12].

Investigation of biochemical changes during aging in mosquitoes on a species by species basis provides the greatest opportunity for discovering age related biochemical changes and could elucidate the relationship between aging, infection, blood feeding and resistance to insecticides. Age associated protein changes can also provide useful biomarkers for the prediction of the age of mosquitoes and other insects, which facilitates ecological studies into insect populations and epidemiological studies into the pathogens they transmit. Changes to gene expression have formed the basis of a novel method of predicting mosquito age [13-15]. Recently, protein biomarkers of aging were identified in the dengue mosquito vector, A. aegypti [12]. Using a similar 2D Difference Gel Electrophoresis (DIGE) approach, we isolated age associated proteins in the major African malaria vector Anopheles gambiae s.s. (hereafter A. gambiae) and the major vector on the Indian subcontinent, Anopheles stephensi. The identity of the aging dependent proteins/peptide spots was then determined by either using matrix-assisted laser desorption ionization tandem time-of-flight (MALDI-TOF/TOF) mass spectrometry or capillary high-pressure liquid chromatography (CapHPLC) mass spectrometry. By comparing changes across two cohorts of mosquitoes for each species, we have identified proteins with robust age-dependent expression patterns including homologs of proteins with known association with aging in other species. Quantitative Western analysis was used to confirm the expression of selected candidate biomarkers.

\section{Materials and methods}

\subsection{Ethics approval}

Ethics approvals were obtained for routine blood feeding from the QIMR Berghofer Medical Research Institute (QIMR HEC P1162), Griffith University (ENV/29/09/HEC) and the Ifakara Health Institute (IHDC/ EC4/CL.N96/2004) human research ethics committees. Written consent was obtained from all volunteers who were involved in blood feeding, and volunteers were given the right to refuse to participate or withdraw from the experiment at any time.

\subsection{Mosquito maintenance}

Two biological replicates (two generations reared at different time points) of A. gambiae were reared at the insectary of Ifakara Health Institute, Tanzania and two biological replicates of $A$. stephensi were reared at the insectary of QIMR Berghofer Medical Research Institute, Australia at $27{ }^{\circ} \mathrm{C}, 70 \%$ humidity, $12: 12 \mathrm{hr}$ day:night lighting. Larvae were fed on Tetramin tropical flakes (Tetra Melle, Germany). Approximately 3000 pupae were required for each cohort. Pupae were transferred into cages measuring $40 \times 40 \times 30 \mathrm{~cm}$ for adult emergence. Adults were fed on $10 \%$ sugar solution daily and blood fed on a human volunteer for 15 min every $7 \mathrm{~d}$. At least 40 female adults were collected $24 \mathrm{~h}$ post emergence and again at 9 and $17 \mathrm{~d}$ post-emergence for A. gambiae and at 9, 17 and $34 \mathrm{~d}$ post-emergence for A. stephensi.
Additional A. stephensi samples were collected at 5, 13 and $25 \mathrm{~d}$ post- 131 emergence for validation of the age associated markers. .

\subsection{Protein extraction and quantification}

133

Only mosquito heads, thoraces and wings were included for protein 134 extraction to exclude possible contamination from human blood pro- 135 teins remaining in abdomens. Five females at 1, 9 and $17 \mathrm{~d}$ of age for 136 A. gambiae and 1, 9, 17 and $34 \mathrm{~d}$ for A. stephensi were used. Extraction 137 and quantification experiments were performed according to the proce- 138 dure described in an accompanying manuscript [16] and the procedure 139 described by Hugo and colleagues [12].

\subsection{D-DIGE, Imaging and processing}

The stock solutions of each of Сy2, Сy3 and Cy5 fluorescent cyanine 142 dyes (GE Healthcare) was prepared by reconstituting the appropriate 143 dye in $5 \mu$ Dimethylformamide (Sigma Chemical Co. Ltd, St Louis, MO, 144 USA) to a concentration of $1 \mathrm{nM}$. Four hundred picomoles of either 145 Cy3 or Cy5 was added to each sample and 2400 pmol of Сy2 was 146 added to the internal standard. Each sample pool was combined with 147 $4.5 \mu \mathrm{l} 100 \times$ ampholytes (Bio-Rad, Richmond, CA, USA), $5.6 \mu \mathrm{l}$ Destreak 148 reagent (GE Healthcare) and made up to $450 \mu \mathrm{l}$ in 2D Buffer. Samples 149 were pipetted onto $24 \mathrm{~cm}$, pH 3-10 immobilised pH gradient strips 150 (Bio-Rad) in rehydration trays and left at room temperature for $4 \mathrm{~h}$ for 151 the strips to absorb the sample. Following absorption, the strips were 152 transferred to a new focussing tray, overlayed with mineral oil and 153 allowed to rehydrate overnight at room temperature. For first dimen- 154 sion separation, the strips were transferred to a dry protean iso- 155 electric focusing tray. The strips were overlayed with fresh mineral oil 156 and iso-electric focussing was performed using the following run condi- 157 tions: current of $50 \mu \mathrm{A}$ per strip, $250 \mathrm{v}$ for $15 \mathrm{~min}, 1000 \mathrm{v}$ for $5 \mathrm{~h}, 158$ $10,000 \mathrm{v}$ for $4 \mathrm{~h}$ and $500 \mathrm{v}$ to reach a total of $80,000 \mathrm{Vh}^{-1}$. Focused strips 159 were equilibrated for 15 min in buffer I containing 6 M Urea, 0.375 M 160 Tris-HCl pH 8.8, 2\% [w/v] SDS, 20\% glycerol and 2\% [w/v] DTT and 161 then for $15 \mathrm{~min}$ in buffer II containing $6 \mathrm{M}$ Urea, $0.375 \mathrm{M}$ Tris-HCl, 2\% 162 [w/v] SDS, 20\% glycerol and 2.5\% [w/v] iodoacetamide. The strips 163 were placed on $12 \%$ acrylamide gels cast in $24 \mathrm{~cm}$ optically clear plates. 164 Electrophoresis was performed in a Protean ${ }^{\circledR}$ Plus Dodeca cell (Bio- 165 Rad) at $5 \mathrm{~mA} / \mathrm{gel}$ for $15 \mathrm{~min}, 10 \mathrm{~mA} /$ gel for $15 \mathrm{~min}$ and $30 \mathrm{~mA} / \mathrm{gel} 166$ until the dye front reached the bottom of the gel. 167

A. stephensi gels were scanned using a Typhoon FLA-9400 fluores- 168 cent imager (GE Healthcare) at $100 \mu \mathrm{m}$ pixel resolution, using the 169 520 band pass (BP) 40 filter for Cy2, 580 BP 30 filter for Cy3 and 170 the $670 \mathrm{BP} 30$ filter for Cy5 emission. A. gambiae gels were scanned 171 using a FLA-9000 Starion fluorescent imager (GE Healthcare) at 172 $100 \mu \mathrm{m}$ pixel resolution using the BPB1 (530DF20) filter for Cy2, DGR1 173 (570DF20/665LP) filter for Cy3 and LPR (665LP) filter for Cy5. Fluores- 174 cent images were processed and analysed using Delta2D version 4.0175 software (Decodon, Greifswald, Germany). Spots on gel images scanned 176 from the same gel were then connected by direct warping and the spots 177 on all gels aligned and normalised for intensity using the Cy2 channel 178 (internal standard images) on each gel with the match vectors tool. 179 All aligned images were fused and thereafter spot validations were 180 transferred to all other images from this fused image as described by 181 Hastie and colleagues [17].

\subsection{In-gel digestion and identification}

Protein spots for identification were manually excised from 2D 184 gels using the method of Hugo and colleagues [12] as described in 185 an accompanying manuscript [16]. In-gel tryptic digests were analysed 186 by either MALDI-TOF/TOF mass spectrometry [18] or separated by 187 CapHPLC and sprayed directly into the ion source of LTQ-Orbitrap XL 188 hybrid MS [19]. 


\subsection{Validation of selected age biomarkers using quantitative Western blot} analysis

Age associated trends observed for selected proteins by 2-D DIGE analysis were validated by measuring protein abundance in independent mosquito lysates using semi-semi quantitative western analysis. Validations were performed for ASTEI06110-PA (ADF/Cofilin), methylmalonate-semialdehyde dehydrogenase mitochondrial acylating protein (MMSA), eukaryotic initiation factor 5A (eIF5A) and manganese superoxide dismutase (SOD2). Rabbit polyclonal antibodies were first raised by the Institute for Medical and Veterinary Science (Adelaide, Australia) against a recombinant GST fusion protein of A. gambiae MMSA and A. stephensi ADF/Cofilin prepared using the pGEX-6P-1 expression vector, expressed using competent BL21 E. coli cells and purified using Gathionlute Sepharose 4B (GE Healthcare) [20]. Affinity purified polyclonal antibodies against aging related A. aegypti protein SOD2 [12] and Aedes albopictus eIF5A [4] were also applied in semi-quantitative Western analyses to determine specificity and cross-reactivity.

Protein was extracted from aged mosquitoes as described above. Five microgrammes of protein was loaded for each sample. Six age points $(1,5,13,17,25 \mathrm{~d}$ old $)$ of individual A. stephensi were used. At least three biological replicates were tested for each protein. Each sample was represented in two lanes on each blot. Additionally, two pooled standard samples were included on each blot to enable standardised comparisons between gels. SDS PAGE was performed using 12\% Mini protean TGX gel (Bio-Rad) at constant 200 V. Proteins were transferred onto Polyvinyl Diflouride membrane (Bio-Rad) using the Trans-blot ${ }^{\circledR}$ turbo $^{\mathrm{TM}}$ transfer system (Bio-Rad) for $30 \mathrm{~min}$ at $25 \mathrm{~V}$ and $1 \mathrm{~A}$. Membranes were briefly rinsed in $100 \%$ methanol for $1 \mathrm{~min}$ and distilled water for 2 min before blocking with Odyssey blocking buffer (LI-COR Biosciences, Lincoln, NE, USA): PBS (1:1) for $1 \mathrm{~h}$ at room temperature while gently shaking. Primary antibodies were used at dilutions stated in Table 1 . Membranes were incubated with the primary antibody for $1 \mathrm{~h}$ at room temperature followed by three washes of $5 \mathrm{~min}$ using PBS/T solution ( $0.1 \%$ Tween in PBS). Secondary antibodies were diluted in Odyssey blocking buffer: PBS (1:1) at the dilutions provided in Table 1 and added to the membranes. Membranes were incubated with the secondary antibody for $1 \mathrm{~h}$ at room temperature while shaking and were washed with PBS/T for five washes of 5 min each and then with $100 \%$ methanol before being dried. Membranes were scanned using an Odyssey infrared imager (Li-cor Lincolin, NE) at an optimised intensity without saturation of pixels on the $700 \mathrm{~nm}$ and $800 \mathrm{~nm}$ channels and $84 \mu \mathrm{m}$ pixel resolution. Membranes were stained in Direct Blue 71 dye and scanned using an Epson expression 1640 XL scanner (Epson, Suwa, Nagano, Japan) at 600 dpi in greyscale.

\subsection{Data analysis}

Expression profiles from DIGE were analysed using the Delta 2D version 4.0 software package (Decodon, Greifswald, Germany). The included multivariate statistical analysis package was used to detect changes in protein abundances significantly associated with age. Normalised spot volumes were compared by analysis of variance (ANOVA) with 1000 permutations, applying an $\alpha$ value of 0.01 and standard Bonferroni correction for multiple testing chosen to minimise false positives being selected for time consuming downstream process- 243 es [21].

Protein identification was performed by searching peptide peak lists 245 detected by TOF/TOF mass spectrometry against in-silico databases of 246 theoretical trypsin digests of published proteins using the MASCOT 247 database search tool (Version 2.2, Matrix Sciences, London). The data- 248 base was compiled from UniProtKB database on 22/05/2012 and from 249 VectorBase database on 26/05/14. A mass tolerance of $100 \mathrm{ppm}$ for pep- 250 tide precursor ions and 0.8 Daltons for fragment ions was applied in all 251 searches. Putative function of hypothetical proteins was inferred using 252 VectorBase database. A detailed description of the procedure used to 253 identify proteins by mass spectrometry is described in our accompany- 254 ing manuscript [16].

Western blot bands were quantified using Odyssey version 3 soft- 256 ware (Li-cor Biosciences). Total protein was determined based on the 257 procedure described by Aldridge and colleagues [22]. Pixel volume 258 was determined from a region from total-protein stained lanes using 259 Multigauge version 3 software (Fujifilm, Midtown West, Tokyo, Japan). 260

To correct for gel loading error, protein quantities were standardised 261 by dividing band pixel volume obtained for Western analysis bands by 262 the pixel volume obtained for total protein. To correct for gel to gel var- 263 iation, the mean standardised protein of the duplicates was divided by 264 the mean of the gel standard duplicates. Data for mean standardised 265 protein quantities were first normalised by a $\log 10[\mathrm{x}+1]$ transforma- 266 tion in statistical package for social sciences (SPSS) version 20 and then 267 One Way ANOVA was used to test the difference of mean normalised 268 protein quantity between ages by selecting age and normalised protein 269 quantity as fixed and dependent variables in the model, respectively. 270 The Tukey post-hoc test was applied to test for changes in band intensi- 271 ty among age groups.

\section{Results}

\subsection{Age-related protein spots for A. stephensi and A. gambiae}

A total of 856 and 693 spots were detected in cohort one and two of 275 A. stephensi respectively (Fig. 1A). For A. gambiae, 773 and 587 protein 276 spots were present on 2D fusion images from cohort one and cohort 277 two, respectively (Fig. 1B). All the spots detected on 2D-DIGE images 278 for both species are presented in our accompanying manuscript [16]. 279 For both species, proteins were selected as candidate age markers only 280 if a significant change was observed for that protein spot in both cohorts 281 between at least two age groups. Out of all the spots detected in 282 A. stephensi, $3.8 \%(\mathrm{~N}=27)$ and $13 \%(\mathrm{~N}=90)$ were differentially 283 expressed with age in cohort one and cohort two, respectively, but 284 only 19 proteins spots were shared between the two cohorts. Five of 285 the A. stephensi age-related protein spots were up-regulated with age 286 (protein spot identification numbers; 391,418, 532,641 and 836) and 287 the remainder were down-regulated with age (Fig. 2A and B). For 288 A. gambiae, out of all the spots detected, 3.6\% $(\mathrm{N}=27)$ and $5 \%(\mathrm{~N}=289$ 30) were found to significantly change in expression with age for cohort 290 one and cohort two, respectively. However, only nine age associated 291 spots were shared between the two cohorts. Three spots showed a 292 steady increase with age (protein spot identification numbers; 539, 293 890 and 66,393) while the rest gradually decreased their expression 294 with age (Fig. $2 \mathrm{~A}$ and $\mathrm{B}$ ).

Table 1

Primary and secondary antibodies and the dilutions used for semi quantitative Western blot analysis.

\begin{tabular}{|c|c|c|c|c|}
\hline Primary antibody & Type & Dilution & Secondary antibody & Dilution \\
\hline $\mathrm{ADF}$ & Rabbit pAs & $1: 1000$ & Goat $\alpha$ rabbit IR800CW (Li-cor) & $1: 20,000$ \\
\hline MMSA & Rabbit pAs & $1: 1000$ & Goat $\alpha$ rabbit IR800CW (Li-cor) & $1: 20,000$ \\
\hline SOD2 & Rabbit pAb & $1: 500$ & Goat $\alpha$ rabbit IR800CW (Li-cor) & $1: 20,000$ \\
\hline eIF5A & Rabbit pAs & $1: 5000$ & Goat $\alpha$ rabbit IR800CW (Li-cor) & $1: 20,000$ \\
\hline
\end{tabular}

pAs-polyclonal antisera.

pAb-polyclonal antibodies. 


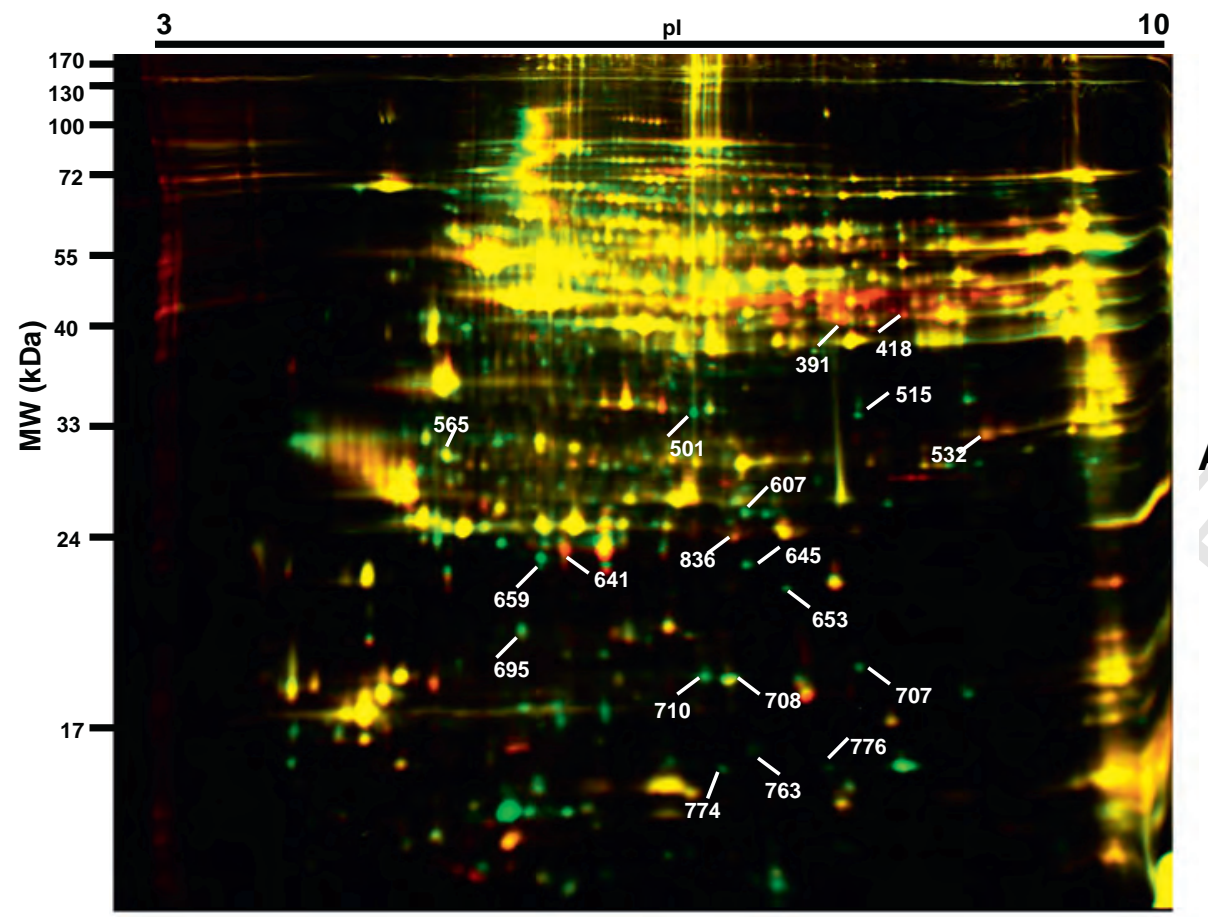

A

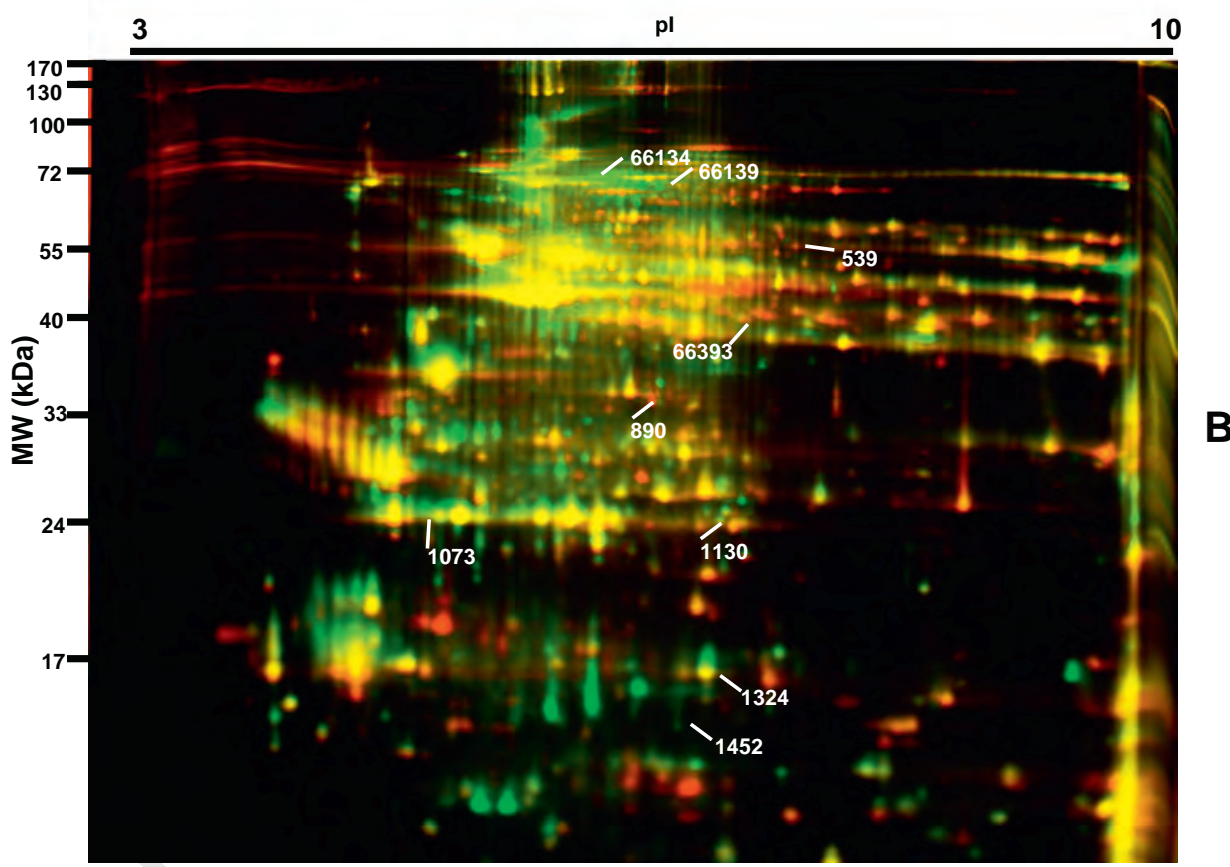

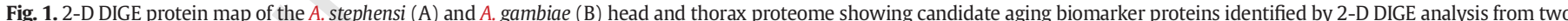

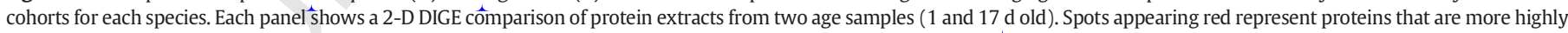

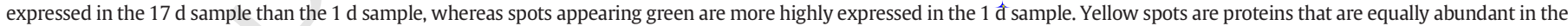
two age samples. (For interpretation of the references to colour in this figure legend, the reader is referred to the web version of this article.)

\subsection{Identification of age-related protein spots}

Protein identification for more visible protein spots on 2D preparative Coomassie stained gels was achieved using MALDI-TOF/TOF MS whereas CapHPLC LTQ-Orbitrap XL hybrid MS was applied to identify less visible spots. Protein spots were then significantly matched to A. stephensi and A. gambiae proteins from UniProtKB and VectorBase databases. Protein identification with MALDI-TOF/TOF MS yielded clear top hits from the databases for those proteins that could be identified (Table 2). However, due to much higher sensitivity of the CapHPLC LTQ-Orbitrap MS there were hits to multiple proteins with MW and pI values in close range to the estimated values from the excised protein/ 306 peptide spot. This was potentially due to the simultaneous detection 307 of overlaying proteins within 2-D gels or due to incomplete focussing 308 of non-target proteins along the horizontal (pI) or vertical (MW) axes. 309 Due to these uncertainties, all proteins identified by CapHPLC LTQ- 310 Orbitrap with MW values within $\pm 5 \mathrm{kDa}$ and pI values within \pm 1 of 311 the actual protein are reported in an accompanying manuscript [16]. 312

Ten A. stephensi and six A. gambiae in-gel tryptic digests were identi- 313 fied using MALDI-TOF/TOF MS and were significantly matched to 314 A. gambiae and A. stephensi published sequences (Fig. 2 and Table 2). 315 The remaining age associated spots were identified using CapHPLC 316 
A
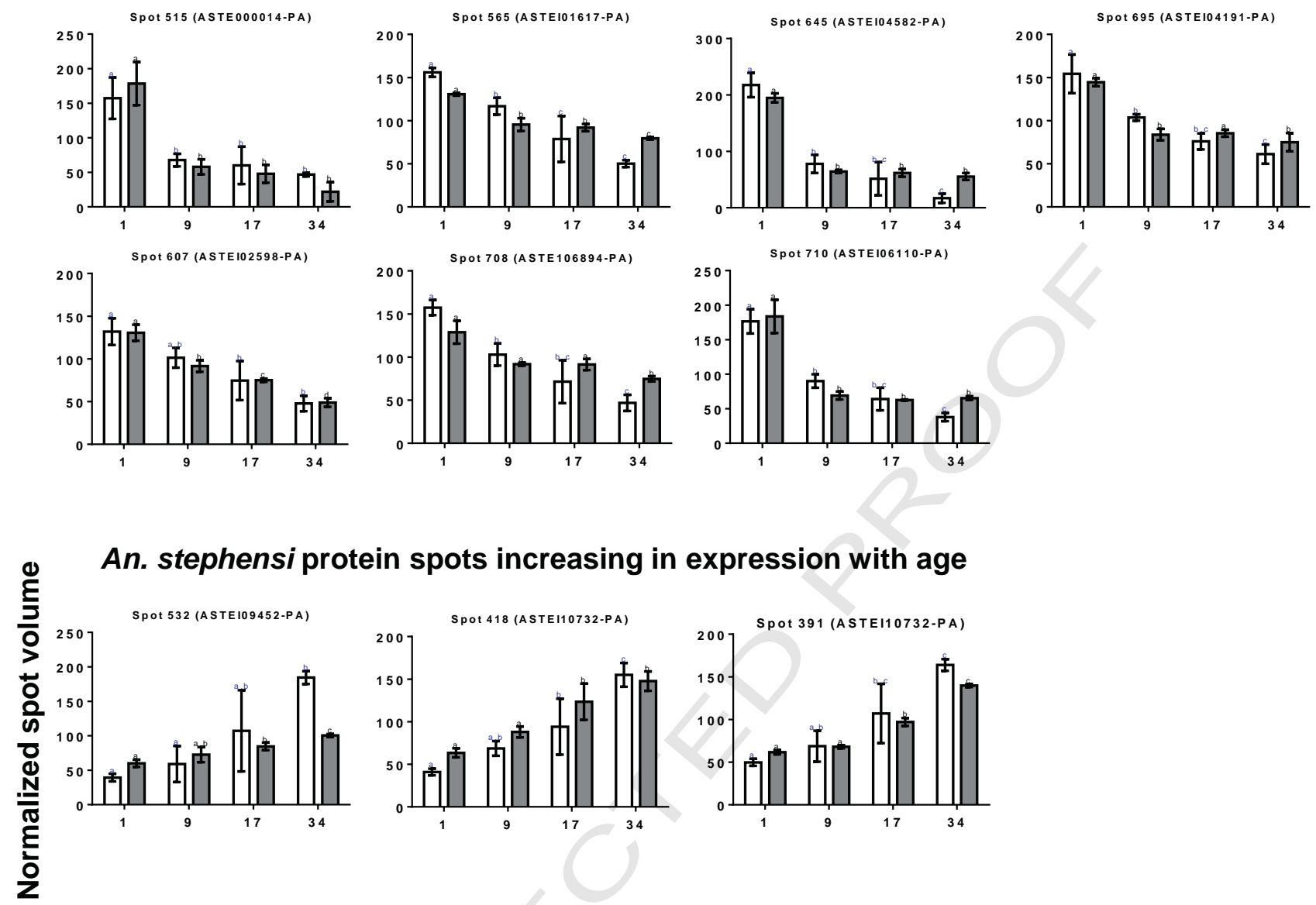

An. gambiae protein spots decreasing in expression with age
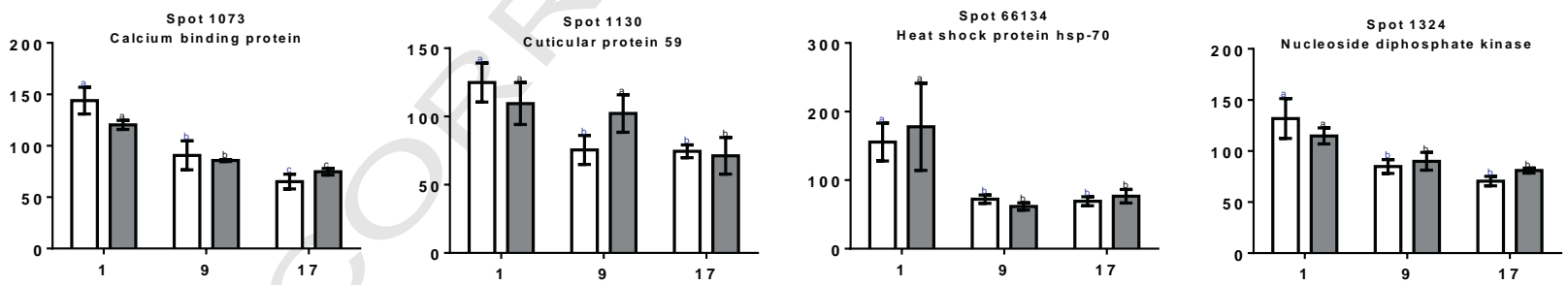

\section{An gambiae protein spots increasing in expression with age}
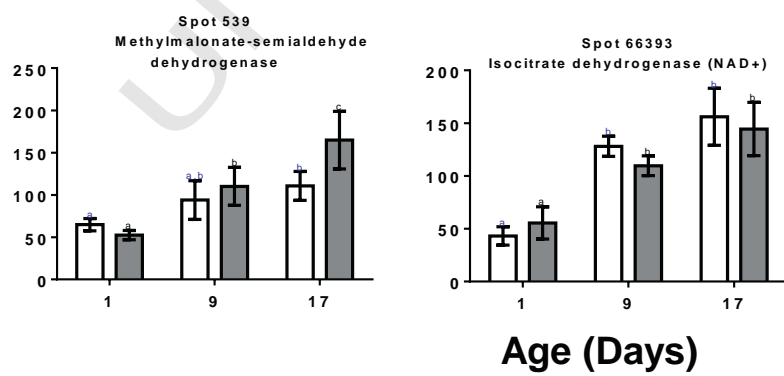

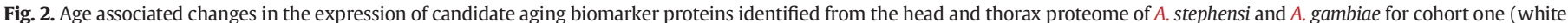

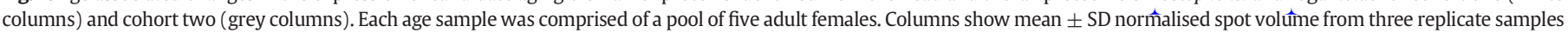

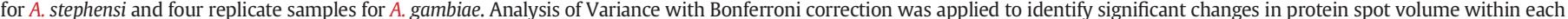

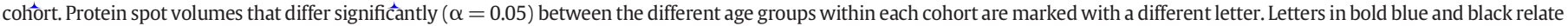

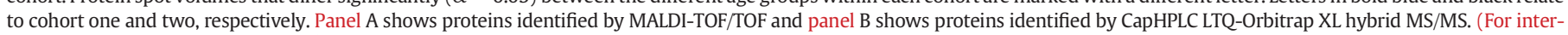
pretation of the references to colour in this figure legend, the reader is referred to the web version of this article.) 
B

\section{An. stephensi}
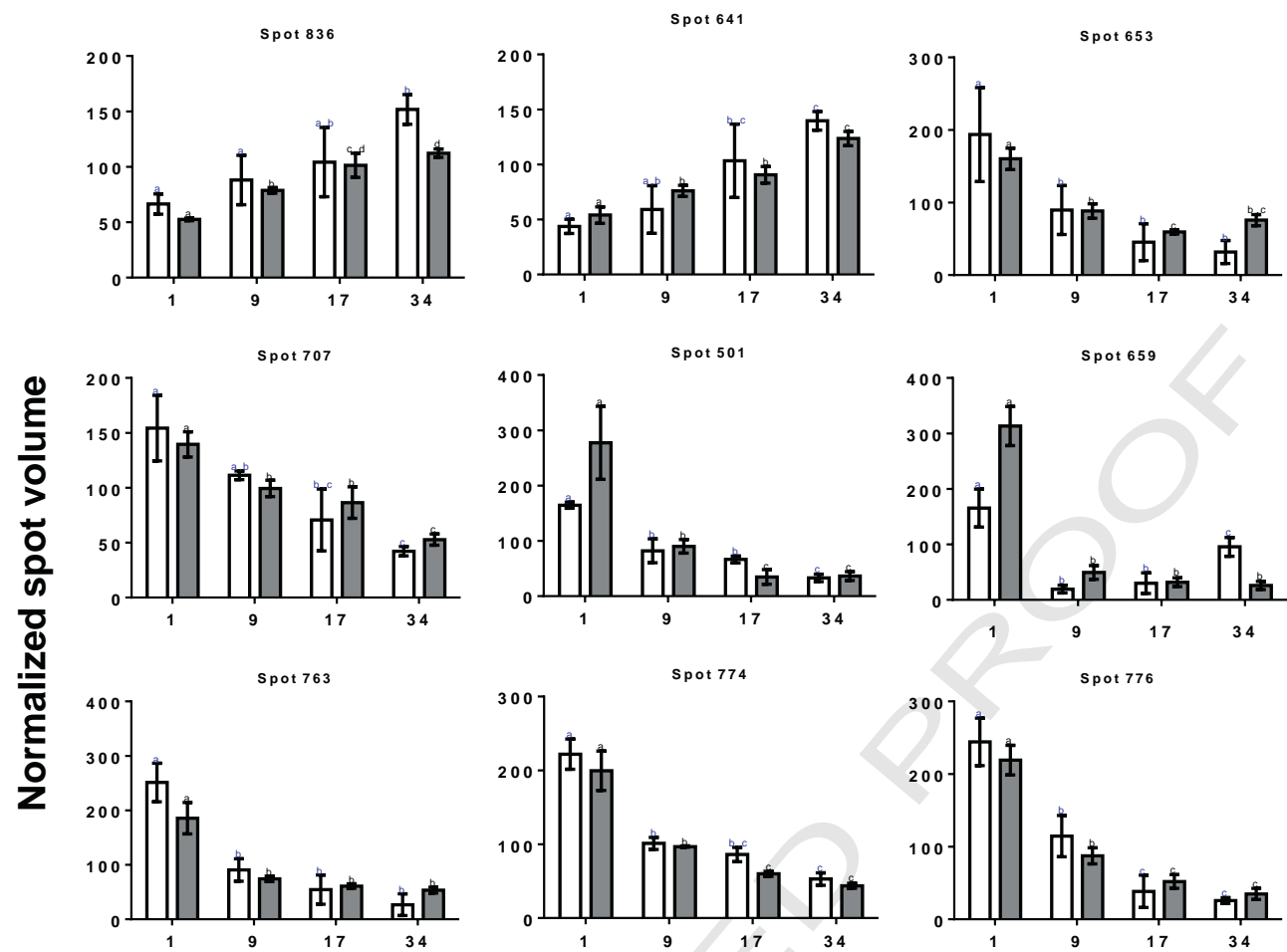

An. gambiae
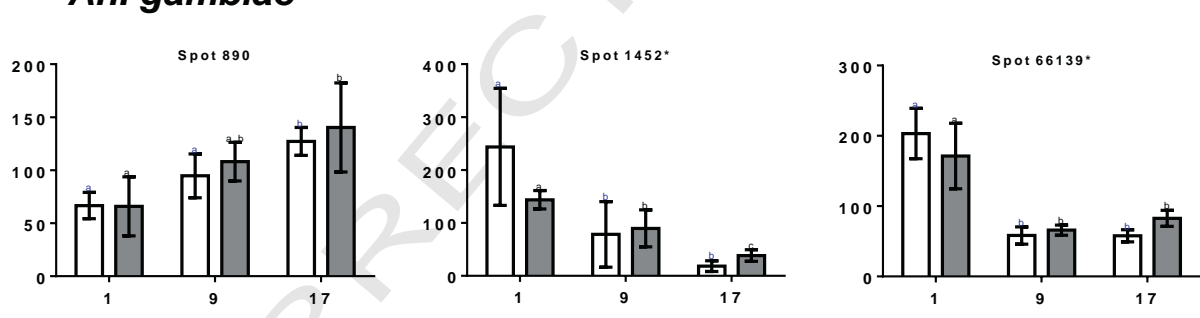

Age (Days)

Fig. 2 (continued).

LTQ-Orbitrap XL hybrid MS (Fig. 2B) and Table 2 in [16]. Two spots (1452 and 66,139) were not visible on Coomassie stained preparatory gels and could therefore not be identified by either of the techniques. Nucleoside diphosphate kinase was found to be age responsive in both A. gambiae and A. stephensi. Four age responsive proteins identified in this study: ADF/Cofilin and eukaryotic translation initiation factor $5 \mathrm{a}$ identified in A. stephensi and heat shock and cuticular proteins identified in A. gambiae were also previously found to be age responsive in A. aegypti [12]. The mass spectrometry proteomics data have been deposited into the ProteomeXchange Consortium [23] database via the PRIDE partner repository with the dataset identifiers PXD002153 and 10.6019/PXD002153.

3.3. Validation of aging-biomarker candidates using quantitative Western blot analysis

\subsubsection{A. stephensi}

Aging trends in the abundance of four protein markers tested by semi quantitative western analysis matched abundance trends yielded by 2-D DIGE analysis. The abundance of ADF decreased significantly 334 with age $(F=6.86$, d.f. $=5, P=0.001$; Fig. $3 \mathrm{~A})$. Comparison between 335 age groups using Tukey post-hoc test indicated that the abundance of 336 ADF in the $1 \mathrm{~d}$ old age group was significantly higher than all other 337 age groups. Similarly, the abundance of eIF5A decreased significantly 338 with age ( $\mathrm{F}=3.79$, d.f. $=5, \mathrm{P}=0.006$; Fig. 3B). The expression in $1 \mathrm{~d} 339$ old mosquitoes was significantly higher than all other age groups except 340 the $5 \mathrm{~d}$ old age group. Although there was an observed increase in band 341 pixel volume for both MMSA and SOD2 proteins, the change was not 342 significant for either MMSA ( $F=2.20$, d.f. $=5, \mathrm{P}=0.100$; Fig. $3 \mathrm{C}$ ) or 343 $\operatorname{SOD} 2(\mathrm{~F}=1.69$, d.f. $=5, \mathrm{P}=0.188$; Fig. 3D).

\section{Discussion}

This study represents the first investigation to determine changes 346 that occur within the proteomes of two major malaria vectors; the 347 African and Asian malaria vectors, A. gambiae and A. stephensi respec- 348 tively, during adult aging. Our examination of over 580 proteins for 349 A. gambiae and 691 proteins for A. stephensi by 2-D DIGE analysis 350 
t2.1 Table 2

t Q1 A. stephensi and A. gambiae age associated spots identified by MALDI-TOF/TOF-mass spectrometry and MASCOT database searching.

A. stephensi and A. gambiae age associated spots identified by MALDI-TOF/IOF

Spot Vector base Putative identity/published protein Name

code

Score to the Peptide sequence

highest

ranked hit

(species name)

(species

name $)^{\mathrm{a}}$

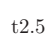

$710 \quad \begin{aligned} & \text { ASTEI06110-PA } \\ & \text { (A. stephensi) }\end{aligned} \quad$ ADF/Cofilin

(A. gambiae)

708 ASTE106894-PA ${ }^{\mathrm{b}} \quad$ Nucleoside diphosphate kinase (A. stephensi)

391 ASTEI10732-PA ${ }^{\mathrm{b}} \quad$ Fructose bisphospate aldolase (A. stephensi)

418 ASTEI10732-PA ${ }^{\mathrm{b}} \quad$ Fructose-bisphospate aldolase (A. stephensi)

565 ASTEI01617-PA $\quad$ 14-3-3 Protein Zeta (A. stephensi)

$$
\text { (1) }
$$

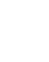

R.YVIFYIRDEK.Q

K.QIDVEVIGDR.N

R.NAEYDSFLEDIQK.G

R.YGLFDFEYMHQCQGTSESSK.K

K.LFLMSWCPDTAK.V

K.LFLMSWCPDTAK.V + Oxidation (M)

K.MLYSSSFDALKK.S

K.YIQATDLSEASR.E

K.YIQATDLSEASREAVEEK.L

K.YIQATDLSEASREAVEEKLR.A

R.EAVEEKLR.A

97.6\% R.GDLCVQVGR.N

(A. gambiae) K.IIERFEAK.G

R.TFIMIKPDGVQR.G

R.TFIMIKPDGVQR.G + Oxidation (M)

K.MLGATNPADSEPGTIR.G

K.ERTFIMIKPDGVQR.G

R.FADIGVENNEDNRR.Q

(A. gambiae) K.KPTAQEIALATVTALR.R

K.KPTAQEIALATVTALRR.T

K.NTPSYQAILENANVLAR.Y

R.IVPIVEPEILPDGDHDLER.C

K.QIVAPGKGILAADESTATCGKR.F

K.GVVDLMGSEGECTTQGLDDLAAR.C

97.8\% R.FADIGVENNEDNRR.Q

(A. gambiae) K.KPTAQEIALATVTALRR.T

K.NTPSYQAILENANVLAR.Y

R.IVPIVEPEILPDGDHDLER.C

K.IGKNTPSYQAILENANVLAR.Y

K.GVVDLMGSEGECTTQGLDDLAAR.C

$\begin{array}{ll} & \text { K.GVVDLMGSEGECTTQGLDDLAA } \\ 97.5 \% & \text { K.AKLAEQSERYDDMAQAMK.S }\end{array}$

(A. aegypti) K.LAEQSERYDDMAQAMK.S

K.LAEQSERYDDMAQAMK.S + Oxidation (M)

K.SVTETGVELSNEER.N

K.SVTETGVELSNEERNLLSVAYK.N

R.NLLSVAYKNVVGAR.R

R.VISSIEQKTESSAR.K

K.MKGDYYR.Y

R.YLAEVATGETR.H

R.HTVVDDSQAAYQDAFEISK.G

K.MQPTHPIR.L

607 ASTEI02598-PA ${ }^{\mathrm{b}} \quad$ Mitochondrial cytochrome $\mathrm{c} 1$ heme

$98.6 \%$ (A. stephensi) protein

(A. gambiae)

K.LSDYFPSPYPNEEAAR.A

695 ASTEI04191-PA ${ }^{\mathrm{b}} \quad$ Eukaryotic translation initiation factor 5a 99\% (A. stephensi)

515 ASTE000014-PA (A. stephensi)

Guanine nucleotide-binding protein subunit beta-2-like 1 protein

(A. gambiae)

$99.7 \%$

(A. gambiae)

R.AANNGAYPPDLSYIALAR. K.DVSTFLVWAAEPYHDER.K

K.VHMVGIDIFTGK.K

R.AEFDSGKEIVCTVLK.S

K.KYEDICPSTHNMDVPNVK.R

K.VWNLANCK.L

K.LWNTLAECK.Y

K.YPDMILSSSR.D

R.LWDLAAGQSTR.R

R.DELSYGIPQKR.L

R.LWDLAAGQSTRR.F

K.LTRDELSYGIPQKR.L

R.FSPNHTNPIIVSAGWDR.V

K.YTIQEDGHSDWVSCVR.F

R.FEDHTKDVLSVAFSVDNR.Q

R.RFEDHTKDVLSVAFSVDNR.Q

K.IDHLGHNGYLNSVSVSPDGSLCTSGGKDCR.A +

Deamidated (NQ)

K.NGDPPQCLSLAWSTDGQTLYAGYSDNIIR.V +

Deamidated (NQ)

645 ASTEI04582-PA ${ }^{\mathrm{b}}$ NADH:ubiquinone dehydrogenase (A. stephensi)

$97.1 \%$

K.YCEAQNNEFMLCR.Q

(A. gambiae) K.TCAQEFTQYANCLDK.S

K.VVYPDATPGLPDDYPRPESK.Y

K.CVLDNMQLERPDYGYFCR.A

\begin{tabular}{|c|c|c|}
\hline $\begin{array}{l}\text { Peptide } \\
\text { score }\end{array}$ & $\begin{array}{l}\% \\
\text { coverage }\end{array}$ & $\begin{array}{l}\text { Calc. } \\
\text { Mw } \\
{[\mathrm{kDa}]}\end{array}$ \\
\hline
\end{tabular}

64

$17.6 \quad 6.74$

30
105

105

84

41

56

53

20

14

26
47

61

(27)

59

12

53
12

12 
Table 2 (continued)

\begin{tabular}{|c|c|c|c|c|c|c|c|c|}
\hline $\begin{array}{r}\text { Spot } \\
\text { ID }\end{array}$ & $\begin{array}{l}\text { Vector base } \\
\text { protein } \\
\text { code } \\
\text { (species name) }\end{array}$ & $\begin{array}{l}\text { Putative identity/published } \\
\text { Name }\end{array}$ & $\begin{array}{l}\text { Score to the } \\
\text { highest } \\
\text { ranked hit } \\
\text { (species }^{\text {name) }}{ }^{\mathrm{a}}\end{array}$ & Peptide sequence & $\begin{array}{l}\text { Peptide } \\
\text { score }\end{array}$ & $\begin{array}{l}\% \\
\text { coverage }\end{array}$ & $\begin{array}{l}\text { Calc. } \\
\text { Mw } \\
{[\mathrm{kDa}]}\end{array}$ & $\begin{array}{l}\text { Calc. } \\
\text { pI }\end{array}$ \\
\hline 532 & $\begin{array}{l}\text { AGAP009833-PA } \\
\text { (A. stephensi) }\end{array}$ & $\begin{array}{l}\text { Voltage-dependent anion-selective } \\
\text { channel }\end{array}$ & $\begin{array}{l}100 \% \\
\text { (A. gambiae) }\end{array}$ & $\begin{array}{l}\text { K.GYHFGLWK.L } \\
\text { M.APPSYSDLGK.Q } \\
\text { R.EFGGLIYQR.C } \\
\text { K.YDLDKDACVR.A } \\
\text { K.VSFDGMFVPHTGSK.T + Oxidation (M) } \\
\text { K.VNNQSQIGLGYQQK.L + Deamidated (NQ) }\end{array}$ & $\begin{array}{l}41 \\
22 \\
35 \\
37 \\
79 \\
37\end{array}$ & 23 & 30.6 & 8.6 \\
\hline 539 & $\begin{array}{l}\text { AGAP002499-PA } \\
\text { (A. gambiae) }\end{array}$ & $\begin{array}{l}\text { Methylmalonate-semialdehyde } \\
\text { dehydrogenase }\end{array}$ & NA & $\begin{array}{l}\text { K.TVTQLWR.E } \\
\text { R.NWIPDLVER.A } \\
\text { K.TLIDAEGDVLR.G } \\
\text { R.GSFLGDCHFYGK.Q } \\
\text { R.CMALSTAVFVGEAR.N } \\
\text { R.AVSFVGSDQAGKYIYER.A } \\
\text { K.TNDWIDLHDPATNEVVTR.V }\end{array}$ & $\begin{array}{l}11 \\
25 \\
19 \\
36 \\
20 \\
32 \\
18\end{array}$ & 16 & 57.3 & 7.9 \\
\hline 1073 & $\begin{array}{l}\text { AGAP007963-PA } \\
\text { (A. gambiae) }\end{array}$ & Calcium binding protein & NA & $\begin{array}{l}\text { K.QTCVGKPYSEFPK.A } \\
\text { R.YQELYAQFMGNENAK.C } \\
\text { K.MMDINNDGLVSIEEYR.Y }\end{array}$ & $\begin{array}{l}47 \\
58 \\
77\end{array}$ & 23 & 22.3 & 4.7 \\
\hline 1130 & $\begin{array}{l}\text { AGAP006829-PA } \\
\text { (A. gambiae) }\end{array}$ & Cuticular protein 59 , RR-1 family & NA & $\begin{array}{l}\text { K.GQYSLVEPDGSVR.T } \\
\text { K.YSYNYGVHDSLTGDVK.S } \\
\text { R.DGDVVKGQYSLVEPDGSVR.T }\end{array}$ & $\begin{array}{l}44 \\
86 \\
72\end{array}$ & 16 & 21.6 & 6.5 \\
\hline 1324 & $\begin{array}{l}\text { AGAP007120-PA } \\
\text { (A. gambiae) }\end{array}$ & Nucleoside diphosphate kinase & NA & $\begin{array}{l}\text { R.GLVGQIMQR.F } \\
\text { R.GLVGQIMQR.F + } 2 \text { Deamidated (NQ) } \\
\text { R.GLVGQIMQR.F + Oxidation (M) } \\
\text { R.TFIMIKPDGVQR.G } \\
\text { R.TFIMIKPDGVQR.G + Oxidation (M) } \\
\text { R.GLVGQIMQRFEAK.G } \\
\text { K.MLGATNPADSEPGTIR.G } \\
\text { R.KMLGATNPADSEPGTIR.G }\end{array}$ & $\begin{array}{l}41 \\
(21) \\
(10) \\
62 \\
(28) \\
12 \\
69 \\
33\end{array}$ & 25 & 18.7 & 6.8 \\
\hline 66393 & $\begin{array}{l}\text { AGAP002728-PA } \\
\text { (A. gambiae) }\end{array}$ & Isocitrate dehydrogenase & NA & $\begin{array}{l}\text { R.SLNLALRK.E } \\
\text { R.MSDGLFLR.C + Oxidation (M) } \\
\text { K.LITEEASNR.V } \\
\text { K.YPEIKFEER.Y } \\
\text { K.FGIPQGAIDSVNR.N } \\
\text { K.FGIPQGAIDSVNR.N + Deamidated (NQ) } \\
\text { K.CSEYTNAICDR.I } \\
\text { K.TLYDNVDVVTIR.E } \\
\text { K.EFNLYANVRPCR.S } \\
\text { R.YLDTVCLNMVQDPR.K + Oxidation (M) } \\
\text { R.DMAQKYPEIKFEER.Y + Oxidation (M) }\end{array}$ & $\begin{array}{l}11 \\
30 \\
25 \\
57 \\
(48) \\
59 \\
17 \\
57 \\
25 \\
19 \\
39\end{array}$ & 28 & 45.8 & 8.4 \\
\hline 66134 & $\begin{array}{l}\text { AGAP010876-PA } \\
\text { (A. gambiae) }\end{array}$ & Heat shock protein hsp-70 & & $\begin{array}{l}\text { K.DAGQIAGLNVLR.V } \\
\text { K.VQSLVQEVFGR.Q } \\
\text { R.AKLETLVGDLIKR.T } \\
\text { K.SDIGEVLLVGGMTR.M + Oxidation (M) } \\
\text { K.MLGSFTLVGIPPAPR.G + Oxidation (M) } \\
\text { K.NAVITVPAYFNDSQR.Q + Deamidated (NQ) } \\
\text { K.VQSLVQEVFGRQPSR.A + } 2 \text { Deamidated (NQ) }\end{array}$ & $\begin{array}{l}85 \\
(81) \\
61 \\
20 \\
54 \\
(85) \\
74\end{array}$ & 13 & 69.5 & 5.5 \\
\hline
\end{tabular}

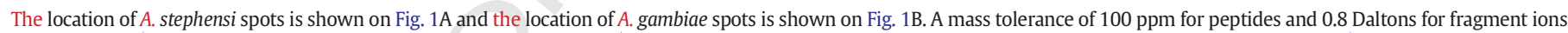
was applied in all searches. Peptides were accepted if the E-value was $<0.05$ and at least two accepted peptide identifications were required to assign protein identification.

a All A. stephensi proteins are hypothetical proteins therefore inferred names correspond to the highest ranked hit to a homologous species indicated in brackets.

b Hypothetical protein.

c A. stephensi protein name was derived from the highest ranked hit to a homologous species.

demonstrated that only a small proportion of the proteins (between 3.6 and 13\%) changed in abundance with age. Further, we confirmed age associated trends by identifying proteins that followed similar significant age-associated abundance changes between two independent cohorts and verified trends for two proteins by semi quantitative western analysis. Nineteen and nine proteins were shown to be significantly age associated in two cohorts of mosquitoes for A. stephensi and A. gambiae, respectively. In keeping with the dengue mosquito A. aegypti [12], at least twice as many proteins decreased in abundance during aging than proteins that increased in abundance. Sixteen candidate proteins were identified by matching peptide mass spectra to proteins within the VectorBase database. The remaining two candidates were not visible on Coomassie stained gels therefore could not be identified by either of the mass spectrometry approaches. Some of the age associated proteins identified in this study are associated with gene/ protein families in which previous association with aging have been reported in other organisms.
Three of the up-regulated proteins identified in our study are 368 metabolic enzymes. These include; a protein similar to fructose- 369 bisphosphate aldolase (FBA), methylmalonate-semialdehyde dehydro- 370 genase (MMSA) and the oxidoreductase isocitrate dehydrogenase 371 (NAD +). Previously, Wang and colleagues found that genes encoding 372 oxidoreductases are down-regulated with age in A. gambiae [14]. FBA 373 is involved in the glycolysis pathway whereas MMSA and Isocitrate de- 374 hydrogenase (NAD +) play roles in pyrimidine metabolism [24] and the 375 tricarboxylic acid cycle, respectively. The up regulation of metabolic 376 proteins identified in this study could be a response to increased energy 377 requirements of the cell to cope with increased age-related oxidative 378 stress. A putative mitochondrial protein of A. stephensi with sequence 379 similarity to cytochrome c1 was found to decrease with age. Cytochome 380 c oxidase activity also appeared to decrease with age in house flies [25]. 381

We identified six candidate age biomarkers that had previously been 382 implicated as age biomarkers in other mosquito species. 1) A heat shock 383 protein-70, 2) a calcium binding protein, 3) ASTEI06110-P; a protein 384 

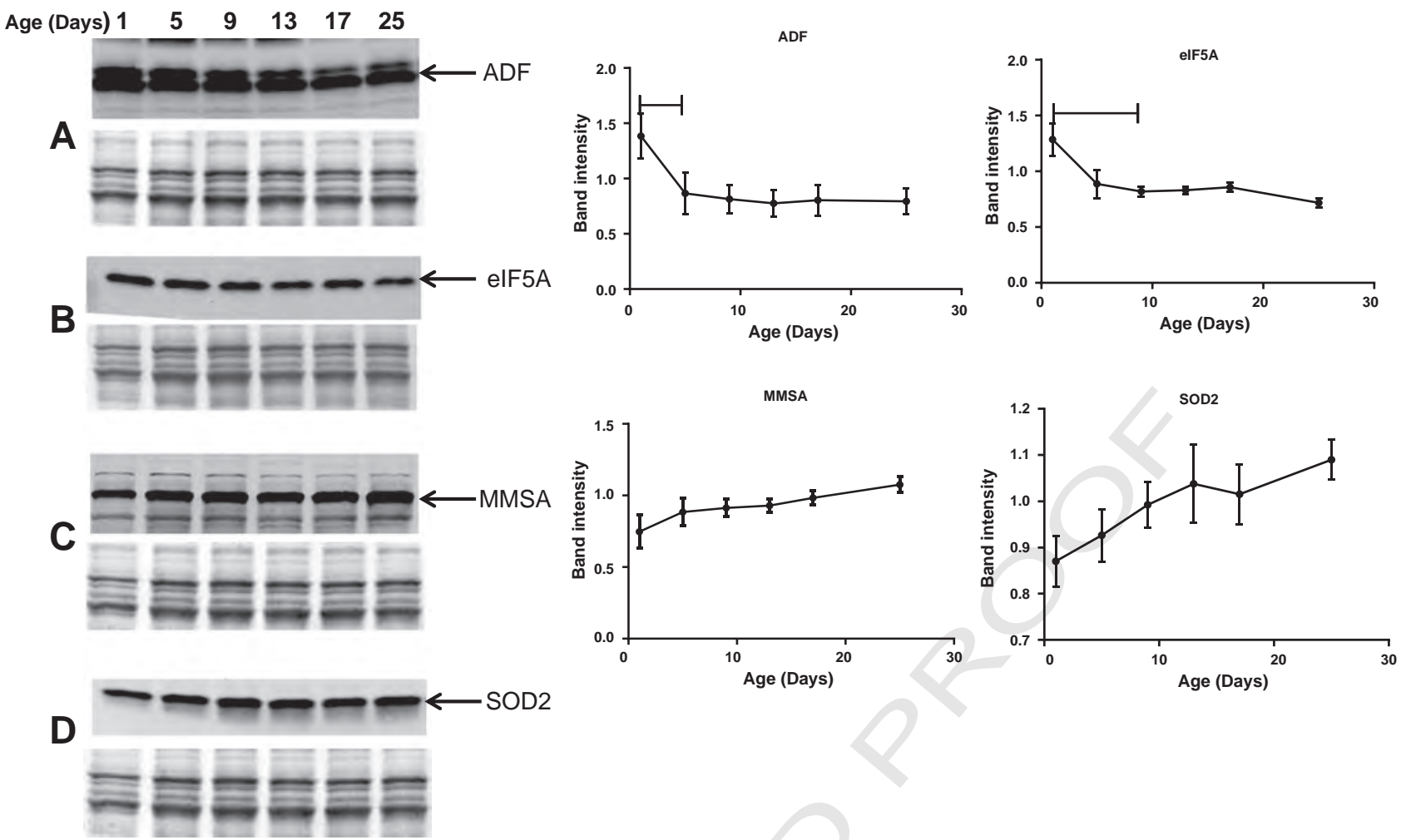

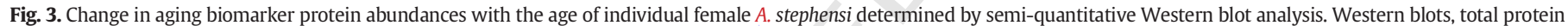

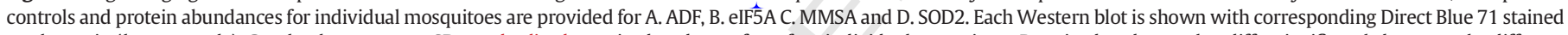

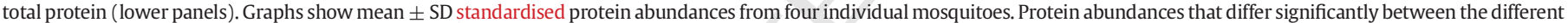
age groups $(\mathrm{P}<0.05)$ are marked with a line.

with $99 \%$ sequence similarity to the Actin depolymerizing factor (ADF)/ Cofilin superfamily, 4) a cuticle protein, 5) ASTEI04191-PA; a hypothetical protein with $99 \%$ sequence similarity to eukaryotic translation initiation factor 5a (eIF5A) and 6) ASTEI01617-PA; a protein with similarity to 14-3-3. Hsp-70 was also found to decrease with age in A. aegypti [12] whereas its expression increased with age in D. melanogaster [26]. Hsps are known to play various roles related to the maintenance of protein stability [8,27-31] hence age-specific induction of hsp-70 could be due to a number of factors including oxidative stress or due to other otherwise undetermined factors associated with aging [8,29-31]. The expression of the calcium binding protein decreased with age in A. gambiae consistent with previous findings at the transcript level in both A. gambiae [13,14] and A. aegypti [32]. Also with a decreasing age associated expression trend was A. stephensi ADF/Cofilin. ADF/Cofilin is involved in the regulation of microfilament turnover and depolymerisation of F-actin filaments as well as reorganization of cytoskeletal structure through Actin-interacting protein 1 [33-36]. An age-dependent down regulation of Actin Depolymerizing Factor protein was also observed in A. aegypti [12]. The age-associated decrease of ADF/Cofilin protein at early ages, now observed across two mosquito genera, illustrates a robust marker of early age and possibly a residual effect from the tissue remodelling that takes place during mosquito metamorphosis. The decreasing expression trend observed for a cuticle protein in A. gambiae follows a similar age-related expression trend to that previously observed for an insect cuticle protein in A. aegypti [12]. It has been reported that the abundance of some cuticular proteins are differentially regulated at different developmental stages [37]. Eukaryotic translation initiation factor $5 A$ was strongly down-regulated with age in A. stephensi as it was in A. aegypti [12]. In eukaryotes, this protein is highly conserved and exists in different isoforms. In plants, initiation factor 5A isoforms are known to regulate senescence and cell division [38,39]. An isoform of 14-3-3 decreased with age in A. stephensi and was also found to decrease with age in A. aegypti [12]. 14-3-3 chaperones are known for their role in apoptosis and cell survival $[40,41]$. 14-3-3 zeta is also a heat-shock related molecu- 418 lar chaperone that dissolves heat-aggregated proteins [42].

A number of candidate age-associated proteins have roles in detox- 420 ification and potentially insecticide resistance or immunity to infection. 421 The most common pyrethroid resistance mechanism, known as "target- 422 site" or "knockdown" resistance is characterised by mutation in the 423 voltage gated sodium channel. It is defined by the ability of mosquito 424 mutants to withstand pyrethroid insecticides for extended periods of 425 time without being knocked down [43]. Alternatively, metabolic resis- 426 tance involves the increased expression of enzymes involved in the 427 metabolism, sequestration or excretion of insecticides. The expression 428 of glutathione transferase e2 has been reported to decrease in older 429 resistant mutants making them less tolerant to insecticide relative 430 to the younger mosquitoes [5]. In this study, we have identified an 431 up-regulated protein in A. stephensi which is most similar to a voltage- 432 dependent anion-selective channel protein in A. gambiae. Other age 433 associated biomarkers identified have been found at elevated abun- 434 dances in infected mosquitoes hence possibly play roles in cellular im- 435 munity. These include eIF5A which was induced in dengue infected 436 A. albopictus cells [4] and a 14-3-3 isoform which was upregulated fol- 437 lowing Plasmodium infection in A. gambiae [3]. Transcription of hsp-70 438 was also upregulated in blood fed A. gambiae mosquitoes but decreased 439 in sugar-fed females [14]. Further work comparing expression levels at 440 different ages is needed to investigate possible involvement in aging 441 associated changes to insecticide resistance and infection susceptibility. 442

Aging specific trends identified by 2-D DIGE analysis were confirmed 443 by Western analysis for two of the biomarkers tested. An age associated 444 decrease between 1 and 5 d old was observed for ADF/Cofilin with no 445 further changes at older ages. An age-dependent decrease in protein 446 abundances of eIF5A also confirmed the trend observed from 2-D 447 DIGE. However, given the previously discussed association of eIF5A 448 with dengue infection [4], the response to Plasmodium infection should 449 be established before this protein is applied as an age biomarker in 450 
Anopheles. Furthermore, MMSA and SOD2 identified in A. gambiae and A. aegypti, respectively, were used to probe Anopheles stephensi to investigate the conservation of aging trends. Age dependent changes were not significant, validating the 2D-DIGE results for this species. The effect of temperature and blood feeding on the expression of aging biomarkers should also be investigated before these findings are generalized to field mosquitoes. If age dependent changes remain robust to these factors, the proteins could be targeted in antibody-based rapid diagnostic assays for the prediction of mosquito age. Proteins with abundance changes greater than 2-fold are likely to be most useful. A rapid diagnostic assay for the prediction of mosquito age in remote locations would be highly sought for the evaluation of vector control interventions in large field studies targeting these primary vectors of malaria. The observed cross-reactivity of A. aegypti and A. albopictus antibodies to Anopheles proteins was pleasing as it demonstrated the potential for a single assay to be applicable to diverse mosquito taxa.

In general, 2D DIGE together with mass spectrometry facilitated the identification of Anopheles proteins with characteristic expression patterns occurring during aging. The expression changes of candidate aging biomarkers were validated by semi quantitative western analysis on individual A. stephensi mosquitoes. The trends were consistent to those obtained by 2-D DIGE analysis of pooled samples and trends observed for A. aegypti [12]. This provides support for the use of the 2D-DIGE and mass spectrometry workflow for the identification of differentially expressed proteins in mosquito vector studies.

\section{Conclusion}

We have identified proteins undergoing aging specific expression changes in two major vectors of malaria. These may illuminate metabolic and other biochemical pathways underlying the relationships between mosquito age and several factors determining pathogen transmission and susceptibility to insecticides. Further, these changes may serve as useful biomarkers for predicting mosquito age, which would facilitate numerous investigations into the biology and epidemiological risk of wild mosquito populations. The conserved aging specific expression patterns of many of the proteins and the demonstrated crossreactivity of antibodies between Anopheles and Aedes vector species suggest that this approach might be useful for the prediction of age-related protein changes in mosquitoes of other genera and insects more generally.

\section{Author contributions}

Conceived and designed the experiments: MTS, LEH, BHK, JJG, PED, RLK. Performed the experiments: MTS, LEH, JM, KAD. Analysed data: MTS, LEH, JM, KAD, MLH, GFK Contributed reagents/materials/analysis tools: BHK, JJG, GFK, PED, RLK. Wrote the paper: MS, LEH. All authors read and approved the final manuscript.

\section{Conflict of interest}

The authors declare that they have no competing interests. The funders had no role in the study design, data collection and analysis, decision to publish, or preparation of the manuscript.

\section{Acknowledgements}

This work was supported by the National Health and Medical Research Council, Australia, Program grant (496601) (http://www. nhmrc.gov.au/);Bioplatforms Australia (http://www.bioplatforms.com. $\mathrm{au} /$ ); the Queensland Government (http://www.qld.gov.au/) and the National Collaborative Research Infrastructure Strategy via Bioplatforms Australia. We thank Dr Wei-June Chen (Chang Gung University, Taiwan) for the generous gift of eIF5A polyclonal antisera. We also acknowledge Griffith Medical Research Council, Griffith University
Postgraduate International Scholarship and QIMR Berghofer Medical 509 Research Institute for awarding MTS a scholarship to undertake this 510 work. Peter A Ryan of Monash University participated in the initial 511 development of the study design and Buddhika Jayakody of the proteo- 512 mics Discovery centre, QIMR Berghofer provided assistance with mass 513 spectrometry. Madeleine Flynn of QIMR Berghofer designed the graph- 514 ical abstract. The authors would like to thank Tovi Lehmann and the 515 anonymous reviewer for their invaluable comments.

\section{References}

[1] C.V. Ariani, P. Juneja, S. Smith, M.C. Tinsley, F.M. Jiggins, Vector competence of Aedes 518 aegypti mosquitoes for filarial nematodes is affected by age and nutrient limitation, 519 Exp. Gerontol. 61 (2015) 47-53.

[2] C. Beier, Malaria parasite development in mosquitoes, Annu. Rev. Entomol. 43521 (1998) 519-543.

[3] T. Lefevre, F. Thomas, A. Schwartz, E. Levashina, S. Blandin, J.-P. Brizard, L. Le 523 Bourligu, E. Demettre, F. Renaud, D.G. Biron, Malaria Plasmodium agent induces 524 alteration in the head proteome of their Anopheles mosquito host, Proteomics 7525 (2007) 1908-1915.

[4] Y.-T. Shih, C.-F. Yang, W.-J. Chen, Upregulation of a novel eukaryotic translation 527 initiation factor 5A (elF5A) in dengue 2 virus-infected mosquito cells, Virol. J. 7528 (2010) $214 . \quad 529$

[5] S. Rajatileka, J. Burhani, H. Ranson, Mosquito age and susceptibility to insecticides, 530 Trans. R. Soc. Trop. Med. 105 (2011) 247-253. 531

[6] C. Jones, A. Sanou, W. Guelbeogo, N.F. Sagnon, P. Johnson, H. Ranson, Aging partially 532 restores the efficacy of malaria vector control in insecticide-resistant populations of 533 Anopheles gambiae s.l. from Burkina Faso, Malar. J. 11 (2012) 24.

[7] J.D. Lines, N.S. Nassor, DDT resistance in Anopheles gambiae declines with mosquito 535 age, Med. Vet. Entomol. 5 (1991) 261-265.

[8] J. Tower, Hsps and aging, Trends Endocrinol. Metab. 20 (2009) 216-222. 537

[9] T.B.L. Kirkwood, Understanding the odd science of aging, Cell 120 (2005) 437-447. 538

[10] D. Harman, Aging: a theory based on free radical and radiation chemistry, J. 539 Gerontol. 11 (1956) 298-300.

[11] B. Chakravarti, D.N. Chakravarti, Oxidative modification of proteins: age-related 541 changes, Gerontology 53 (2007) 128-139.

[12] L.E. Hugo, J. Monkman, K.A. Dave, L.F. Wockner, G.W. Birrell, E.L. Norris, V.J. Kienzle, 543 M.T. Sikulu, P.A. Ryan, J.J. Gorman, Proteomic biomarkers for ageing the mosquito 544 Aedes aegypti to determine risk of pathogen transmission, PLoS ONE 8 (2013) 545 e58656.

[13] P.E. Cook, S.P. Sinkins, Transcriptional profiling of Anopheles gambiae mosquitoes for 547 adult age estimation, Insect Mol. Biol. (2010)http://dx.doi.org/10.1111/j.1365-2583. 548 2010.01034.x.

[14] M.-H. Wang, O. Marinotti, A.A. James, E. Walker, J. Githure, G. Yan, Genome-wide 550 patterns of gene expression during aging in the African malaria vector Anopheles 551 gambiae, PLoS ONE 5 (2010) e13359.

[15] M.-H. Wang, O. Marinotti, D. Zhong, A.A. James, E. Walker, T. Guda, EJ. Kweka, J. 553 Githure, G. Yan, Gene expression-based biomarkers for Anopheles gambiae age 554 grading, PLoS ONE 8 (2013) e69439.

[16] M.T. Sikulu, J. Monkman, K.A. Dave, M.L. Hastie, Kitching R. Dale PE, G.F. Killeen, B. 556 Kay, J. Gorman Jeffrey, L.E. Hugo, Description of techniques applied to determine 557 change in protein abundance with age in the heads and thoraces of 558 Anopheles gambiae s.s. and Anopheles stephensi, J. Proteomics (2015) (submitted 559 for publication)

[17] M.L. Hastie, M.J. Headlam, N.B. Patel, A.A. Bukreyev, U.J. Buchholz, K.A. Dave, E.L. 561 Norris, C.L. Wright, K.M. Spann, P.L. Collins, The human respiratory syncytial virus 562 nonstructural protein 1 regulates type I and type II interferon pathways, Mol. Cell. 563 Proteomics 11 (2012) 108-127. 564

[18] K.A. Dave, M.J. Headlam, T.P. Wallis, J.J. Gorman, Preparation and analysis of proteins 565 and peptides using MALDI TOF/TOF mass spectrometry, Curr. Protoc. Protein Sci. 566 16.13 (2011) $1-21$

[19] D.A. Joubert, K.R. Blasdell, M.D. Audsley, L. Trinidad, P. Monaghan, K.A. Dave, K.G. 568 Lieu, R. Amos-Ritchie, D.A. Jans, G.W. Moseley, Bovine ephemeral fever rhabdovirus 569 $\alpha 1$ protein has viroporin-like properties and binds importin $\beta 1$ and importin 7, J. 570 Virol. 88 (2014) 1591-1603. 571

[20] J.V. Frangioni, B.G. Neel, Solubilization and purification of enzymatically active gluta- 572 thione S-transferase (pGEX) fusion proteins, Anal. Biochem. 210 (1993) 179-187. 573

[21] J.M. Bland, D.G. Altman, Multiple significance tests: the Bonferroni method, BMJ 310574 (1995) 170.

[22] G.M. Aldridge, D.M. Podrebarac, W.T. Greenough, I.J. Weiler, The use of total protein 576 stains as loading controls: an alternative to high-abundance single-protein controls 577 in semi-quantitative immunoblotting, J. Neurosci. Methods 172 (2008) 250-254. 578

[23] J.A. Vizcaíno, E.W. Deutsch, R. Wang, A. Csordas, F. Reisinger, D. Rios, J.A. Dianes, Z. 579 Sun, T. Farrah, N. Bandeira, ProteomeXchange provides globally coordinated prote- 580 omics data submission and dissemination, Nat. Biotechnol. 32 (2014) 223-226. 581

[24] J.R. Sokatch, L.E. Sanders, V.P. Marshall, Oxidation of methylmalonate semialdehyde 582 to propionyl coenzyme A in Pseudomonas aeruginosa grown on valine, J. Biol. Chem. 583 243 (1968) 2500-2506

[25] R. Sohal, Aging, cytochrome oxidase activity, and hydrogen peroxide release by 585 mitochondria, Free Radic. Biol. Med. 14 (1993) 583-588.

26] V. King, J. Tower, Aging-specific expression of Drosophila hsp22, Dev. Biol. 207587 (1999) 107-118. 
[27] M.E. Feder, G.E. Hofmann, Heat-shock proteins, molecular chaperones, and the stress response: evolutionary and ecological physiology, Annu. Rev. Physiol. 61 (1999) 243-43.

[28] L. Pirkkala, P. Nykänen, L. Sistonen, Roles of the heat shock transcription factors in regulation of the heat shock response and beyond, FASEB J. 15 (2001) 1118-1131.

[29] J. Tower, Heat shock proteins and Drosophila aging, Exp. Gerontol. 46 (2011) 355-362.

[30] J.C. Wheeler, E.T. Bieschke, J. Tower, Muscle-specific expression of Drosophila hsp70 in response to aging and oxidative stress, Proc. Natl. Acad. Sci. 92 (1995) 10408-10412.

[31] J. Yang, J. Tower, Expression of hsp22 and hsp70 transgenes is partially predictive of Drosophila survival under normal and stress conditions, J. Gerontol. A Biol. Sci. Med. Sci. 64A (2009) 828-838.

[32] P.E. Cook, L.E. Hugo, I. Iturbe-Ormaetxe, C.R. Williams, S.F. Chenoweth, S.A. Ritchie, P.A. Ryan, B.H. Kay, M.W. Blows, S.L. O'Neill, The use of transcriptional profiles to predict adult mosquito age under field conditions, Proc. Natl. Acad. Sci. 103 (2006) 18060-18065.

[33] J.R. Bamburg, B.W. Bernstein, ADF/Cofilin, Curr. Biol. 18 (2008) R273-R275.

[34] T.V.S. Tammana, A.A. Sahasrabuddhe, K. Mitra, V.K. Bajpai, C.M. Gupta, Actindepolymerizing factor, $\mathrm{ADF} / \mathrm{cofilin}$, is essentially required in assembly of Leishmania flagellum, Mol. Microbiol. 70 (2008) 837-852.

[35] C.G. Dos Remedios, D. Chhabra, M. Kekic, I.V. Dedova, M. Tsubakihara, D.A. Berry, N.]. Nosworthy, Actin binding proteins: regulation of cytoskeletal microfilaments, Physiol. Rev. 83 (2003) 433-473.
[36] S. Ono, K. Mohri, K. Ono, Microscopic evidence that actin-interacting protein 1 ac- 613 tively disassembles actin-depolymerizing factor/Cofilin-bound actin filaments, J. 614 Biol. Chem. 279 (2004) 14207-14212.

[37] C.J. Chihara, D.J. Silvert, J.W. Fristrom, The cuticle proteins of Drosophila 616 melanogaster: stage specificity, Dev. Biol. 89 (1982) 379-388. 617

[38] J.E. Thompson, M.T. Hopkins, C. Taylor, T.-W. Wang, Regulation of senescence by eu- 618 karyotic translation initiation factor 5A: implications for plant growth and develop- 619 ment, Trends Plant Sci. 9 (2004) 174-179.

[39] H. Feng, Q. Chen, J. Feng, J. Zhang, X. Yang, J. Zuo, Functional characterization of the 621 Arabidopsis eukaryotic translation initiation factor 5A-2 that plays a crucial role in 622 plant growth and development by regulating cell division, cell growth, and cell 623 death, Plant Physiol. 144 (2007) 1531-1545.

[40] G.W. Porter, F.R. Khuri, H. Fu, Dynamic 14-3-3/client protein interactions integrate 625 survival and apoptotic pathways, Semin. Cancer Biol. 16 (2006) 193-202. 626

[41] H. Xing, S. Zhang, C. Weinheimer, A. Kovacs, A.J. Muslin, 14-3-3 proteins block 627 apoptosis and differentially regulate MAPK cascades, EMBO J. 19 (2000) 349-358. 628

[42] M. Yano, S. Nakamuta, X. Wu, Y. Okumura, H. Kido, A novel function of 14-3-3 pro- 629 tein: $14-3-3 \zeta$ is a heat-shock-related molecular chaperone that dissolves thermal- 630 aggregated proteins, Mol. Biol. Cell 17 (2006) 4769-4779.

[43] T.G.E. Davies, L.M. Field, P.N.R. Usherwood, M.S. Williamson, DDT, pyrethrins, pyre- 632 throids and insect sodium channels, IUBMB Life 59 (2007) 151-162. 633 